\title{
A qualitative study on the Development of Healthy Tennis Clubs in the Netherlands
}

\author{
B. Pluim ${ }^{1}$, N. Pluim ${ }^{2}$ and J. Earland ${ }^{3}$ \\ ${ }^{1}$ Royal Netherlands Lawn Tennis Association, Amersfoort, The Netherlands, ${ }^{2}$ Ondersteuning bij onderzoek, Wageningen, \\ The Netherlands and ${ }^{3}$ School of Population, Community and Behavioural Sciences, University of Liverpool, Liverpool, \\ $L 693 B X, U K$
}

An unhealthy lifestyle, specifically smoking, lack of physical activity and an unhealthy diet, is a major contributing factor to morbidity and mortality in the Netherlands ${ }^{(1)}$. Tennis is second only to soccer in terms of popularity, and the Royal Netherlands Lawn Tennis Association (KNLTB) has almost 700000 registered members ${ }^{(2)}$. Therefore, the creation of 'healthy tennis clubs' could have a positive influence on an important proportion of the Dutch population. The overall aims of the study were to explore factors that facilitate or hinder the implementation of health-promoting measures at Dutch tennis clubs in the Netherlands and to identify interventions that would help the clubs to take on a health promoting role.

A maximum variation, purposive sampling strategy ${ }^{(3)}$ was used to identify and recruit board members $(n 16)$ from ten Dutch tennis clubs. The sample included clubs from all five geographical regions and of different sizes. Data were collected using in-depth interviews based on an interview guide ${ }^{(3)}$. The interviews explored what steps the club had taken, if any, to create a health promoting environment, and what the respondents perceived to be the barriers to tennis clubs taking on a health promoting role. The data were analysed using thematic content analysis ${ }^{(3)}$. A number of steps were taken in order to enhance rigour including cross-checking of the coding and interpretation of the data by a second analyst ${ }^{(4)}$.

The four themes that emerged from the analysis were: provision of healthy foods, injury prevention and health services, social health and safety around the club. Here the findings with respect to the provision of healthy foods will be presented. The steps already taken by the clubs included the provision of complete meals and fresh foods instead of unhealthy snacks and beverages (mostly during competitions and tournaments when there were more customers). Having a supportive management board was identified as being a key facilitating factor. Clubs whose board members felt that it was essential to be able to provide healthy food generally had a wider selection of fresh and healthy foods than clubs with little or no board support. Parents were often seen as strong advocates of healthy food and exercised their influence through the junior committees. Problems arising in the kitchen were cited as important barriers to providing healthy food at tennis clubs. These included the short shelf-life of fresh foods, and the additional kitchen equipment, knowledge and skills required to prepare healthy meals instead of simple snacks. Board members felt that the strict hygiene codes required under Dutch law made it more difficult to prepare and serve foods, especially when working with volunteers.

This study showed that even though most board members reported that they were in favour of providing healthy foods, the barriers encountered prevented clubs from doing so. A number of recommendations were made to the KNLTB. These included the need to integrate general health promotion as well as healthy eating into existing training programmes for all ages and the creation of a website on which health promotion information can be found easily. Finally, a set of standards should be developed to identify clubs that have health promoting programmes, enabling clubs that meet the minimum criteria to obtain certification as a 'healthy tennis club'.

1. Oers JAM van (2002) Gezondheid op Koers? Volksgezondheid Toekomst Verkenning 2002 [Health on Course? The 2002 Dutch Public Health Status and Forecasts Report]. http://www.rivm.nl/bibliotheek/rapporten/270551001.pdf (accessed February 2011).

2. KNLTB (2010) KNLTB jaarverslag 2009. Amersfoort: KNLTB. http://www.knltb.nl/cms/showpage.aspx?id=375 (accessed December 2010).

3. Patton MQ (2002) Oualitative Research and Evaluation Methods, 3rd ed. London: Sage Publications.

4. Barbour RS (2001) Br Med J 322, 1115-1117. 